\title{
Experimental Investigation Of The Real Contact Arc Length Measurement In The Cylindrical Plunge Grinding
}

\author{
Jingzhu PANG ${ }^{1, a^{*}}$, Chongjun $\mathrm{WU}^{1,2, \mathrm{~b}}$, Beizhi $\mathrm{LI}^{1, \mathrm{c}}$, Yaqin $\mathrm{ZHOU}{ }^{1, \mathrm{~d}}$ \\ and Steven Y. LIANG ${ }^{2, \mathrm{e}}$ \\ ${ }^{1}$ Donghua University, Shanghai, China \\ ${ }^{2}$ Georgia Institute of Technology, Atlanta, USA \\ apangjz@dhu.edu.cn, ${ }^{\mathrm{b}}$ wcjunm@126.com, ${ }^{\mathrm{c}}$ lbzhi@dhu.edu.cn, ${ }^{\mathrm{d}}$ zhouyaqin@dhu.edu.cn, \\ esteven.liang@me.gatech.edu
}

\begin{abstract}
The real contact arc length in grinding is one of the most important indicators in investigating of the material removal mechanism for precision machining. It is generally affected by a combination of plastic and thermal deformations in the machining process. This paper will provide a systematic investigation of the contact arc length in the cylindrical grinding of titanium alloy Ti-6Al-4V. A series of single grit experiments and grinding temperature measurements, together with FEM simulation, will be utilized to determine the real contact arc length. The contact behavior between a grinding wheel and the workpiece was investigated by the contact time in the workpice surface temperature curves. It was found that in FEM simulation, the real contact length was about 2 times of the geometric length. With the experimental results of the different grinding parameters, the real contact lengths calculated by temperature curves were about 1.5 - 2 times of the geometric length.
\end{abstract}

\section{Introduction}

The grinding contact length and the undeformed chip thickness are two of the most important geometric parameters in describing the mechanics of grinding. In surface grinding, the contact arc between the grinding wheel and workpiece can be distinguished into three stages: rubbing, ploughing and cutting. If both grinding wheel and the workpiece were considered as rigid bodies, the real contact length would be the value of the geometry contact length, which is defined as:

$$
l_{g}=\left(1+\frac{v_{w}}{v_{s}}\right) \sqrt{a_{p} \cdot d_{e}}
$$

\footnotetext{
* Corresponding author:pangjz@dhu.edu.cn
} 
where $-l_{g}$ is the geometry contact length, $v_{w}$ is the workpiece velocity, $v_{s}$ is the wheel speed, $a_{p}$ is the grinding depth, $d_{e}$ is equivalent diameter of the grinding wheel, equal to $\frac{d_{s} \cdot d_{w}}{d_{s}+d_{w}}$, $d_{s}$ is the diameter of the grinding wheel and $d_{w}$ is the diameter of the workpiece. The difference between the real contact length $l_{r}$ and the geometrical contact length $l_{g}$ is a result of the deformation of the grinding wheel and the workpiece under the effect of the abrasive grain size, wheel hardness and workpiece material etc.

If the real contact length is much different from the geometry one, the assumption of the geometry contact length replacing the geometry contact length will cause a significant error. The workpiece and wheel deflection can produce a considerable change in the real length of the contact zone by as much as $100 \%$ increase of the geometrical contact length, and Rowe et al.[1] proposed the calculation formula of the actual arc length as shown in Eq.2, in which the deformation of the contact area caused by the normal force was added.

$$
l_{r}=\left(a_{p} d_{e}+8 R_{r}^{2} F_{n}^{\prime} d_{e}\left(K_{s}+K_{w}\right)\right)^{0.5}
$$

where- $K_{s}=\frac{1-\mu_{s}^{2}}{\pi E_{s}}, K_{w}=\frac{1-\mu_{w}^{2}}{\pi E_{w}}, E_{s}, E_{w}$ are the moduli of elasticity and the grinding wheel and the workpiece, $\mu_{s}^{2}, \mu_{w}^{2}$ are the Poisson ratios of the grinding wheel and the workpiece, $F_{n}^{\prime}$ is a specific normal grinding force. $R_{r}$ is the roughness factor. The estimation of the actual contact length must be complemented by experimental work. Taking into account the geometry of the process, the difficulties of direct measurement become obvious. Due to this fact, several researchers have developed different methodologies for the indirect measurement of the actual contact length. Verkerk [2] used a single pole thermocouple embedded in the workpiece surface to measure contact length. The following studies [3][4][5] also use this classical methods to measure the contact length in their researches. Another approach to obtain traces of grains left on the surface of the workpiece by sudden interruption of the grinding process, including quick-stop test [6], the two-half-slot method [7]. And the APS system [8] was applied to the contact length study. The measured results showed that the real contact length in grinding is longer than the geometric contact length.

The above described literature all focused on the surface grinding, and the precise estimation of contact length in the cylindrical grinding is not mentioned. In cylindrical grinding, the contact arc between the grinding wheel and workpiece can be distinguished into five stages which may correspond to the action of an active grain through the contact area, rubbing, ploughing, cutting, ploughing, and rubbing[9]. The contact area in cylindrical grinding is different from that of the surface grinding. The objective of this paper is to study the contact length in the cylindrical grinding.

\section{The Contact Length in Single Abrasive Grain Grinding Simulation}

The simulation of cylindrical grinding with single abrasive grain $(\mathrm{CBN})$ on the titanium alloy workpiece (Ti-6Al-4V) was studied by using FEM software DEFROM-3D[10]. The height of the grain is $0.12 \mathrm{~mm}$ with a top cone angle $106^{\circ}$. The diameter of the grinding wheel is $400 \mathrm{~mm}$ and the diameter of the workpiece is $\varnothing 20 \mathrm{~m}$. The simulation process was solved by using the Newton-Raphson method with the step increment $1 \times 10^{-8} \mathrm{~s}$, Normalized Cockcroft\& Latham fracture criterion $\mathrm{C}=0.06$, shear friction coefficient 0.25 , thermal transmissivity $40 \mathrm{~N} / \mathrm{s} / \mathrm{mm} / \mathrm{C}$ and the heat transfer coefficient between the workpiece and the 
external environment $1 \mathrm{~N} / \mathrm{s} / \mathrm{mm} / \mathrm{C}$. As shown in Figure. 1, the actual grinding length is mainly composed of five stages. After the rubbing and ploughing for almost half of the real contact length, the abrasive grains will start to cut the workpiece.

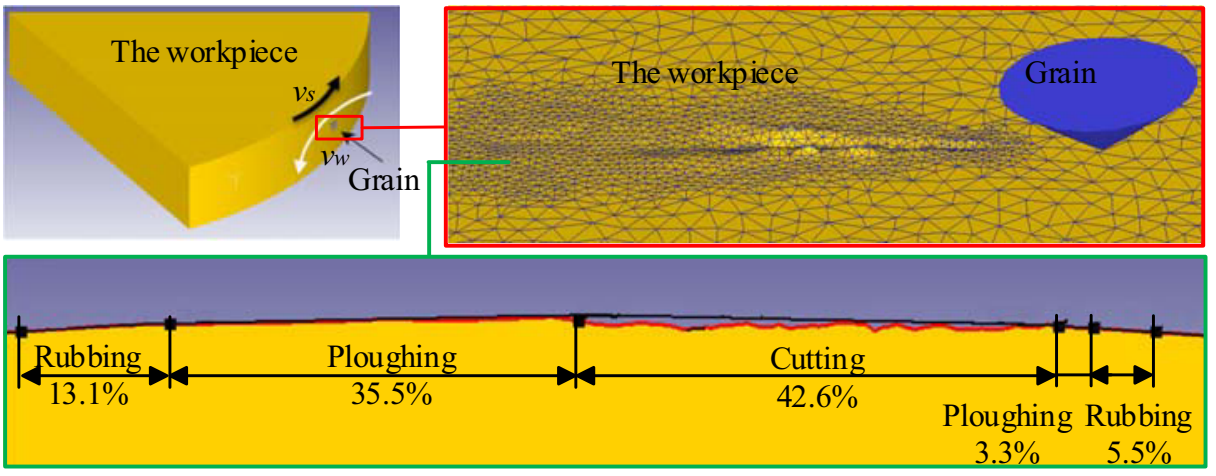

( Single CBN grain, Ti-6Al-4V, $v_{s}=120 \mathrm{~m} / \mathrm{s}, v_{w}=0.12 \mathrm{~m} / \mathrm{s}, a_{p}=17 \mu \mathrm{m} / \mathrm{r}$ )

Figure. 1 The grinding contact area in FEM simulation

The actual real contact length of the different grinding parameters obtained by FEM was shown in TABLE 1. The geometric contact length is $0.57 \mathrm{~mm}$ by the Eq. 1 . The real length is about 2 times that of the geometry.

TABLE 1 THE REAL CONTACT LENGTH IN DEFORM-3D

\begin{tabular}{ccccccc}
\hline No. & $\begin{array}{c}\text { Wheel } \\
\text { speed } \\
v_{s}[\mathrm{~m} / \mathrm{s}]\end{array}$ & $\begin{array}{c}\text { Workpiece } \\
\text { speed } \\
v_{w}[\mathrm{~m} / \mathrm{s}]\end{array}$ & $\begin{array}{c}\text { Grinding } \\
\text { depth } \\
a_{p}[\mu \mathrm{m} / \mathrm{r}]\end{array}$ & $\begin{array}{c}\text { Real } \\
\text { length } \\
l_{r}[\mathrm{~mm}]\end{array}$ & $\begin{array}{c}\text { Geometry } \\
\text { length } \\
l_{g}[\mathrm{~mm}]\end{array}$ & $l_{r} / l_{g}$ \\
\hline 1 & 30 & 0.12 & 17 & 1.130 & 0.5713 & 1.9779 \\
2 & 60 & 0.12 & 17 & 1.125 & 0.5702 & 1.9731 \\
3 & 90 & 0.12 & 17 & 1.163 & 0.5698 & 2.0411 \\
4 & 120 & 0.12 & 17 & 1.163 & 0.5696 & 2.0417 \\
5 & 150 & 0.12 & 17 & 1.163 & 0.5695 & 2.0421 \\
\hline
\end{tabular}

\section{The Real Contact Length with the Single Abrasive Grain}

The grinding experiment with the single abrasive grain (CBN) was carried out on a high-speed grinding machine MS1310A. The diameter of the grinding wheel substrate installed with the single abrasive grain is $400 \mathrm{~mm}$, the workpiece diameter is $80 \mathrm{~mm}$, the grinding depth is $5 \mu \mathrm{m}$, the wheel speed is $90 \mathrm{~m} / \mathrm{s}$, the workpiece velocity is $0.1 \mathrm{~m} / \mathrm{s}$ and the geometric contact length will be $0.58 \mathrm{~mm}$. The surface of the workpiece (Ti-6Al-4V) grinded by the single abrasive grain was obtained by Hirox video microscopy KH-7700, as show in Figure. 2. The length of the ploughig and the cutting stages can be measured directly from the surface of the workpiece after grinding, but it is difficult to define the starting and ending point of the two rubbing stages (in and out). In Figure. 2, the ploughing and the rubbing were obvious and the real contact length is $0.89 \mathrm{~mm}$ in the morphology of the grinding mark and $l_{r} / l_{g}$ in this experiment is 1.53 . 

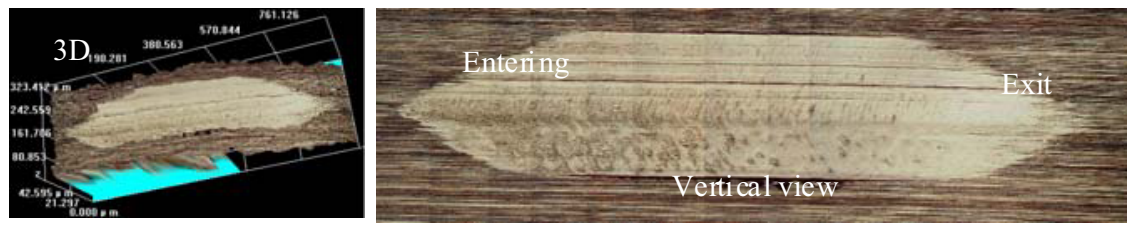

Figure. 2 The morphology of the grinding mark

\section{The Real Contact Length Deduced by Grinding Temperature Curves}

Temperature measurement experiments of the cylindrical grinding were carried out on the high speed grinding machine MGKS1332/H, as shown in Figure. 3. A vitrified CBN grinding wheels $(14 \mathrm{~A} 1400 \times 32 \times 76 \times 5 \times 22 \mathrm{~B} 91 \mathrm{~V} 175$, WINTER) with $400 \mathrm{~mm}$ in diameter and $22 \mathrm{~mm}$ in width was used for the cylindrical grinding. To obtain the workpiece temperature, the embedded method with a K-type thermocouple was used. Both of the wires of the thermocouple were flatted from $100 \mu \mathrm{m}$ to $35 \mu \mathrm{m}$. In the calibration conditions used, the sensor is fast enough to measure the surface temperature. The hot junction of the thermocouple was formed at the workpiece surface while grinding. A high frequency acquisition system allows the signal to be measured at the abrasive grain scale so that the activity of grains and the contact stability between the thermocouple and the wheels during grinding can be studied. The maximum sampling rate of grinding temperature used was 100KHZ. It is difficult to distinguish the entrance and exit of the real contact length in the temperature curve of low sampling rate, but temperature sparks appeared by the abrasive grains in the contact area of the grinding wheel and the workpiece can be measured in high sampling rate. With the increase of the sampling rate, the action of the abrasive grain on the workpiece is reflected better by the change of the grinding temperature.

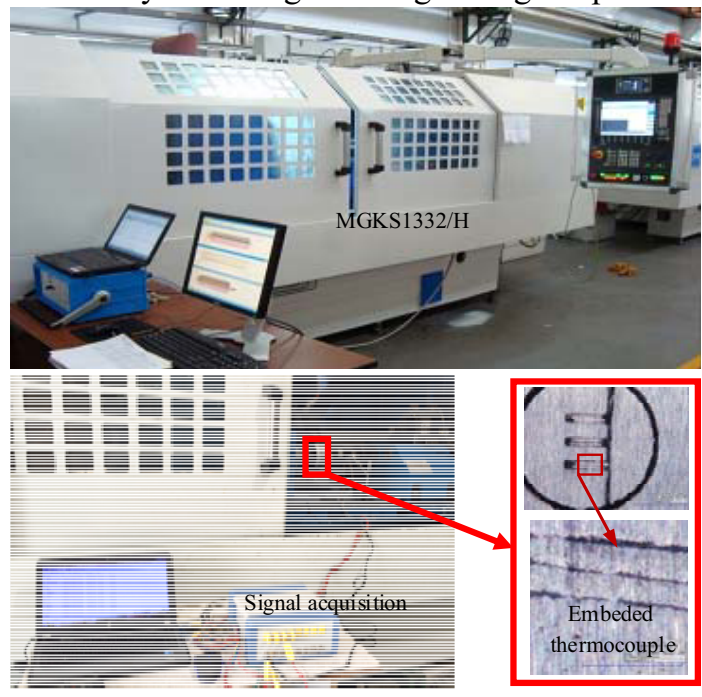

Figure. 3 Experimental setup 


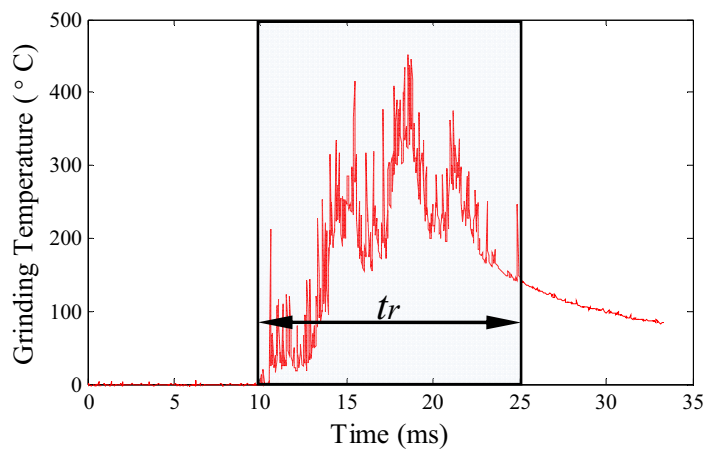

Figure. 4 Temperature measured by the thermocouple

With the wheel speed $60 \mathrm{~m} / \mathrm{s}$, the workpiece velocity $0.1 \mathrm{~m} / \mathrm{s}$ and the grinding depth $5 \mu \mathrm{m} / \mathrm{r}$, the temperature curve measured by the thermocouple sensor with the sampling rate $30 \mathrm{KHZ}$ was shown in Figure. 4. The actual wheel/thermocouple contact time $t_{r}$ was measured on the experimental temperature curve from the first temperature peak to the last one by the active grains. The temperature sparks appeared in the time interval $t_{r}$, which was also indicated that the contact time of the grinding wheel and the workpiece in this period.

The real contact length $l_{r}$ can be calculated by,

$$
l_{r}=t_{r} \times v_{w}
$$

\section{Results and Discussions}

The grinding temperatures of different grinding parameters were tested and the real contact length was calculated, as shown in Table 2. Though with the same grinding parameters, the real contact length will be different from vary experiments. The actual grinding arc length is the average value of the 15-20 experiments results in the same grinding process parameters.

TABLE 2 THE REAL CONTACT LENGTH BASED ON TEMPERATURE EXPERIMENT

\begin{tabular}{ccccccc}
\hline No. & $\begin{array}{c}\text { Wheel speed } \\
v_{s}[\mathrm{~m} / \mathrm{s}]\end{array}$ & $\begin{array}{c}\text { Workpiece velocity } \\
\left.v_{w} \mathrm{~m} / \mathrm{s}\right]\end{array}$ & $\begin{array}{c}\text { Grinding depth } \\
a_{p}[\mu \mathrm{m} / \mathrm{r}]\end{array}$ & $\begin{array}{c}\text { Real length } \\
\left.l_{r} \mathrm{~mm}\right]\end{array}$ & $\begin{array}{c}\text { Geometry length } \\
l_{g}[\mathrm{~mm}]\end{array}$ & $\begin{array}{c}l_{r} / l_{g} \\
-\end{array}$ \\
\hline 1 & 60 & 0.1 & 5 & 1.37 & 0.79 & 1.73 \\
2 & 60 & 0.15 & 5 & 1.46 & 0.79 & 1.85 \\
3 & 60 & 0.2 & 5 & 1.52 & 0.79 & 1.92 \\
4 & 90 & 0.1 & 5 & 1.33 & 0.79 & 1.68 \\
5 & 120 & 0.1 & 5 & 1.31 & 0.79 & 1.66 \\
6 & 120 & 0.12 & 8 & 1.73 & 1.01 & 1.71 \\
7 & 120 & 0.12 & 14 & 2.09 & 1.33 & 1.57 \\
8 & 120 & 0.12 & 17 & 2.21 & 1.47 & 1.50 \\
9 & 120 & 0.24 & 17 & 2.78 & 1.47 & 1.89 \\
10 & 120 & 0.48 & 17 & 3.02 & 1.47 & 2.05 \\
\hline
\end{tabular}


There was large difference between the real contact length and the geometry length. Therefore, there is a great error if the real contact length is replaced by the geometric contact length. Therefore, there is a great error if the real contact length is replaced by the geometric contact length. Experimental results of the temperature measurement showed an excellent fit with the results of the previous FEM simulation and the single grain experiment.

By the comparison of the real and the geometry contact length, the contact length ratio $l_{r} / l_{g}$ was not a constant. As shown in Figure. 5(a), the contact length ratio decreased with the increase of the grinding wheel speed, and the reason is that the grinding force decreased with the increase of the grinding wheel speed. And with the increase of the workpiece speed and the material removal rate, the normal grinding force was increased which lead to the increase of the real contact length and the contact length, as shown in Figure. 5(b). With the increase of the grinding depth, the contact length ratio decreased, as shown in Figure. $5(\mathrm{c})$.
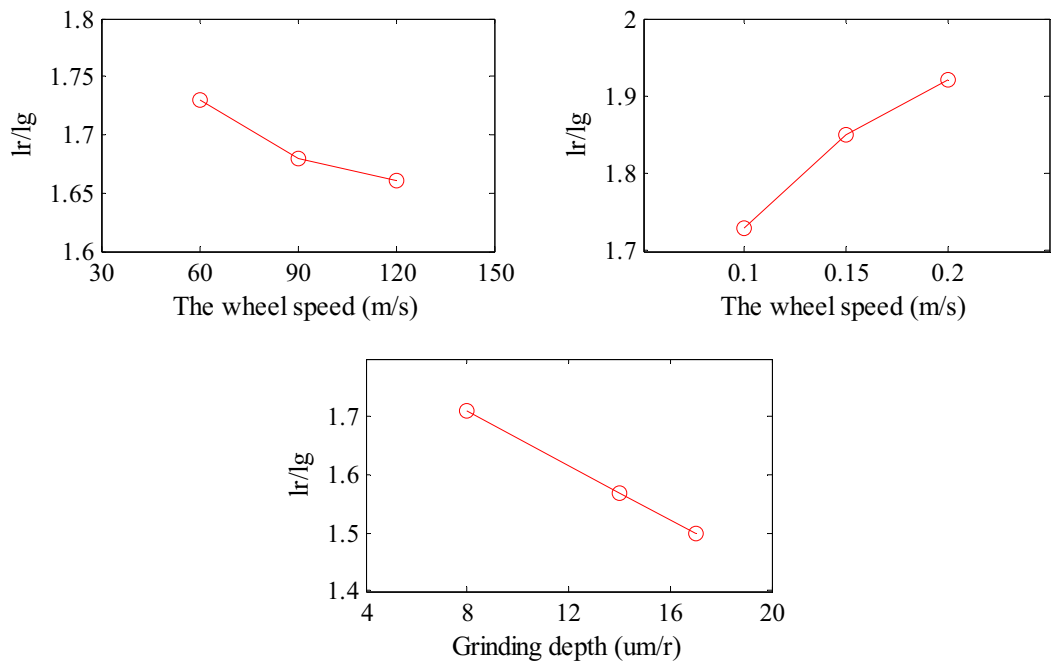
(a) $v_{w}=0.1 \mathrm{~m} / \mathrm{s} 、 a_{p}=5 \mu \mathrm{m} / \mathrm{r}$
(b) $v_{s}=60 \mathrm{~m} / \mathrm{s} 、 a_{p}=5 \mu \mathrm{m} / \mathrm{r}$
$v_{s}=120 \mathrm{~m} / \mathrm{s} 、 v_{s}=0.12 \mathrm{~m} / \mathrm{s}$

Figure. 5 Effect of grinding parameters on the contact length ratio

According to Table 2, the corresponding empirical equation can be derived to characterize the relationship between the real contact length $l_{r}$, the wheel speed $v_{s}(\mathrm{~m} / \mathrm{s})$, the workpiece speed $v_{w}(\mathrm{~mm} / \mathrm{s})$ and the grinding depth $a_{p}(\mathrm{~mm} / \mathrm{r})$ for the grinding contact area of $\mathrm{CBN}$ wheels and Ti6Al4V workpice. The regression coefficients were obtained by solving the multiple linear regression equation, and the regression equation of $l_{r}$ can be established as following:

$$
l_{r}=1.61 v_{s}^{-0.0009} v_{w}^{0.029} a_{p}^{-0.0136}
$$

\section{Conclusion}

The experiments for calculating the real contact length of the cylindrical grinding by the surface temperature curve of the workpiece was constructed. The results shows that the 
contact time between the wheel and the workpiece in the grinding contact area can be effectively calculated based on the thermal sparks of the surface temperature curve of the workpiece. Through the experimental statistics, it is found that the real contact length is 1.5-2 times of the results of the traditional geometric calculation. These results were proved by the real contact length in the FEM simulation and the single grain experiment. The important influence of plastic deformation and thermal deformation on real contact area in cylindrical grinding is demonstrated, which provides the basis for the calculation of temperature distribution in the grinding zone.

\section{Acknowledgement}

This work is a part of National Science and Technology Major Project of the Ministry of Science and Technology of China (2011ZX04016-041-06). The authors wish to record their gratitude to their generous supports.

\section{References}

1. Rowe, W. B., et al. The Effect of Deformation on the Contact Area in Grinding. CIRP Annals - Manufacturing Technology 42.1(1993):409-412.

2. Verkerk J. The real contact length in cylindrical plunge grinding. Annals of the CIRP. 24.1(1975): 259-264.

3. Qi, H. S., W. B. Rowe, and B. Mills. Experimental investigation of contact behaviour in grinding. Tribology International 30.4(1997):283-294.

4. Lefebvre, A., et al. Numerical analysis of grinding temperature measurement by the foil/workpiece thermocouple method. International Journal of Machine Tools \& Manufacture 46.14(2006): 1716-1726.

5. Pombo, Iñigo, et al. Contact length estimation in grinding using thermocouple measurement and numerical simulation. International Journal of Advanced Manufacturing Technology 59.1-4(2011):83-91.

6. Brown RH, Wager JG, Watson JD. An examination of the work-wheel interface using an explosive device to suddenly interrupt the surface grinding process. Annals of the CIRP 25.1(1977):143-146.

7. Gu, D. Y., and J. G. Wager. New Evidence on the Contact Zone in Grinding Contact Length, Sliding and Cutting Regions. CIRP Annals - Manufacturing Technology 37.1(1988):335-338.

8. Zhou, Z. X., and C. A. V. Lutterwelt. The Real Contact Length between Grinding Wheel and Workpiece - A New Concept and a New Measuring Method. CIRP Annals - Manufacturing Technology 41.1(1992):387-391.

9. Zhu D H. Research on High-Speed External Cylindrical Grinding Mechanism of Difficult-To-Cut Materials and Its Surface Integrity, Donghua University, 2011.

10. Pang, Jing Zhu, et al. Temperature Simulation in High-Speed Grinding by Using Deform-3D. Advanced Materials Research 189-193(2011):1849-1853. 